\title{
Constitutive Modeling of High-Strength Steel Designed for Ballistic Protection
}

\author{
Pawel Zochowski ${ }^{1, *}$, Mariusz Zielenkiewicz ${ }^{1}$ \\ ${ }^{1}$ Military Institute of Armament Technology, 7 Wyszynskiego str. 05-220 Zielonka, Poland
}

\begin{abstract}
Constitutive behaviour of a high-strength nanostructured bainitic steel NANOS-BA® was investigated in the article. A few types of mechanical tests under varying strain rates were carried out to determine the values of constants of Johnson-Cook flow and fracture models for the analysed material. In quasi-static conditions $\left(8 \times 10^{-3} \mathrm{~s}^{-1}\right)$ the material samples were subjected to uniaxial tension and compression tests. In a high strain rates conditions $\left(2,7 \times 10^{3} \mathrm{~s}^{-1}\right)$ the Taylor impact test was carried out. On the basis of the data obtained from mechanical tests the constitutive model of the NANOS-BA® steel was built. It was then validated to determine the extent and degree of compliance between the numerical and experimental observations. The examples of combined numerical-experimental analyses of protective structures containing investigated material were shown. Small differences between the both types of results testifies that determined constants of Johnson-Cook equation may properly reproduce actual behaviour of the material, and the numerical model allows the preliminary evaluation of the effectiveness of armours containing layers of analysed grade of steel.
\end{abstract}

\section{Introduction}

Designing of effective and light armours consisting of new materials and subsequent evaluation of their protective capability may be very expensive and timeconsuming when it is based only on experimental methods (bulletproof tests). When the materials with unknown protective properties are used it is very difficult to predict e.g. the minimal thickness of the layers that provide protection against a specific type of projectile. Therefore a large number of trials is usually required to obtain an optimal variant of armour.

Currently, numerical methods are often used in the armour designing process. They allow to shorten the time and reduce the costs of the research, especially in the initial stage, where they help to identify the best variants of construction limiting the number of necessary experimental tests. But the reliability of the numerical results is strongly dependent on the quality of the material models and their parameters characterization. Therefore the aim of the study presented in the article was building of the numerical model of a high-strength bainitic steel designed for armour applications. The examples of simulations in which the developed model was used are also presented.

\section{Materials}

The NANOS-BA® steel which was analysed in the article is a high-carbon bainitic steel developed in the Institute for Ferrous Metallurgy in Poland [1]. Its chemical composition (wt. $\%$ : $0,55 \mathrm{C}-2,0 \mathrm{Mn}-1,8 \mathrm{Si}-$
$1,37 \mathrm{Cr}-0,7 \mathrm{Mo}-0,11 \mathrm{~V})$ together with a specific heat treatment provide a large share of nano-grains in its structure. As a result the steel is characterized by a high yield strength $R_{e}>1,3 \mathrm{GPa}$, tensile strength $R_{m}>2,0 \mathrm{GPa}$ and hardness $H V_{10}>640$ with a reasonable level of ductility $A_{5}>12 \%$. Such combination of properties is desirable in the armour applications. Additionally, relatively small mass of alloying elements decreases the cost of production of nanostructured bainitic steel in comparison to other steels of similar mechanical properties (maraging steels).

Chemical composition and heat treatment parameters of NANOS-BA® steel were submitted to the Patent Office of the Republic of Poland [1].

\section{Constitutive modelling}

Appropriate selection of material models and subsequent accurate determination of the values of constants in their equations are crucial for obtaining reliable simulation results. Steel structures in a high-velocity impact conditions are affected by high strain rates, large and varied types of stresses and strains and a failure. Numerical model for steel should take into account all these effects.

\subsection{Flow and fracture model}

The most popular model used to describe the behaviour of metallic materials in the high-velocity impact scenarios was proposed by Johnson and Cook (J-C) [2].

Corresponding author: zochowskip@witu.mil.pl 
It is coupled with the fracture criterion and it takes into account the strengthening and thermal softening of the material together with the increase of the strain rate and temperature respectively. The flow stress in the JC model is defined as a function [2]:

$$
\sigma=\left(A+B \varepsilon^{n}\right)\left(1+C \ln \frac{\dot{\varepsilon}}{\dot{\varepsilon}_{r e f}}\right)\left[1-\left(\frac{T-T_{0}}{T_{m}-T_{0}}\right)^{m}\right]
$$

where A, B, C, m, n are material constants and $T, T_{0}, T_{m}$ - room, reference and melting temperatures, $\sigma$ - stress, $\boldsymbol{\varepsilon}$-strain, $\dot{\boldsymbol{\varepsilon}}$ - strain rate, $\boldsymbol{\varepsilon}_{\boldsymbol{e} e f}-$ reference strain rate

Johnson and Cook developed also the failure model, in which the fracture strain depends on the stress triaxiality, strain rate and temperature and is described by the following equation:

$$
\varepsilon_{f}=\left[D_{1}+D_{2} e^{D_{3} \sigma^{*}}\right]\left\lfloor 1+D_{4} \ln \dot{\varepsilon}\right]\left[1+D_{5} \frac{T-T_{0}}{T_{m}-T_{0}}\right]
$$

where $D_{1}-D_{5}$ are fracture model constants, $\sigma^{*}$ is the stress triaxiality ratio.

Fracture occurs when the damage parameter D reaches the value of 1 :

$$
D=\sum \frac{\Delta \varepsilon}{\varepsilon_{f}}=1
$$

where $\Delta \varepsilon$ is the incremental effective plastic strain and $\varepsilon_{\tilde{\rho}}$ is the equivalent plastic fracture strain.

The model of destruction of $\mathrm{J}-\mathrm{C}$ is referred as an "instantaneous" - after detecting the fracture of an element its stiffness and strength are reduced to zero.

\subsection{Material characterization tests}

At low strain rates, quasi-static tension and compression tests were carried out on a universal testing machine with a constant displacement of $5 \mathrm{~mm} / \mathrm{min}$ until the fracture of the samples. Samples for the tests were prepared from the NANOS-BA® steel plates (Fig. 1).

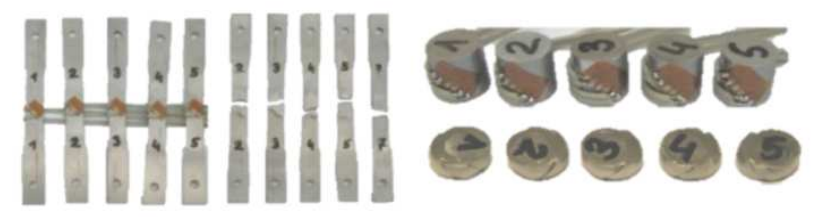

Fig. 1. Sample before and after tension and compression tests.

The test data was used to obtain engineering stressstrain curves. Plotting of true stress-strain curves was more complicated. When the sample is being deformed during tension or compression (necking or barrelling respectively) the state of stress is no longer uniaxial. In such a case, determination of the true stress-strain in relation requires a continuous measurement of the degree of deformation of the sample and the area of its crosssection. In this work, the values of true stresses and strains were determined in a simplified manner using the coupled numerical-experimental method. Firstly the compression test was reproduced with a finite element modelling. The aim was to determine the set of $\mathrm{J}-\mathrm{C}$ material constants that provide similar forcedisplacement curve as in experiment. In the numerical compression test, the gauge points were placed on the sample, in the middle of its height, where the maximum deformations were predicted. Displacement of the gauge points in the radial direction was measured, thus determining the growth of cross-sectional radius of the sample (Fig. 2).
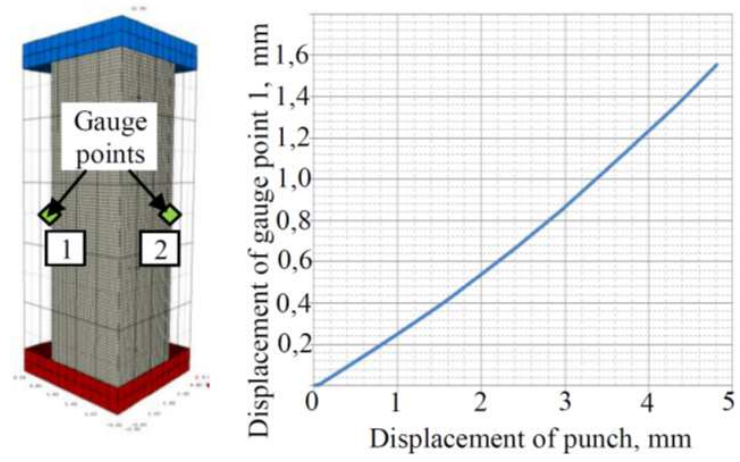

Fig. 2. Determination of current cross-section area of sample.

Finally the data from the experiments and the cross sections of the samples from simulations were used to conversion of engineering stress-strain curves to the true ones. Assuming negligible volume changes, the true stresses and strains in sample were calculated from the following equations:

$$
\begin{gathered}
\sigma_{\text {true }}=\frac{P}{A_{i}} \\
\varepsilon_{\text {true }}=2 \ln \frac{A_{i}}{A_{0}}
\end{gathered}
$$

where $A_{1}$ current cross-section area of the sample and $A_{0}$ initial cross-section area of the sample

The yield strength of NANOS-BA® steel measured in quasi-static tension tests was about $\boldsymbol{R}_{e 02}=1.5 \mathrm{GPa}$. This value is close to the one obtained in compression tests $\boldsymbol{R}_{\boldsymbol{e} 02}=1.5 \mathrm{GPa}$. The fracture strain for NANOSBA® steel measured with extensometers was $\varepsilon_{\digamma}=0.36$. The stress at fracture was: engineering $\sigma_{f e n g}=3.9 \mathrm{GPa}$ and $\sigma_{\text {rtrue }}=2.7 \mathrm{GPa}$.

The value of the dynamic yield strength was determined during the Taylor impact tests. They were carried out at a deformation rate of $2.5 \times 10^{3}-3.2 \times 10^{3} \mathrm{~s}^{-1}$, which corresponded to impact velocities of $160-205 \mathrm{~m} / \mathrm{s}$. After the impact, samples were examined to eliminate the damaged ones. Following deformations of the samples were measured: initial diameter $d$, initial length, $L$, length after deformation $L_{F}$, length of the undeformed part $l_{F}$. The value of dynamic yield strength of the material was calculated using the classic Taylor theory and equation:

$$
Y=\frac{\frac{1}{2} \rho v^{2}\left(1-\frac{l_{f}}{L_{f}}\right)}{\left(1-\frac{L_{f}}{L}\right) \ln \left(1-\frac{L}{l_{f}}\right)}
$$

where $\rho$ density, $v$ impact velocity. 


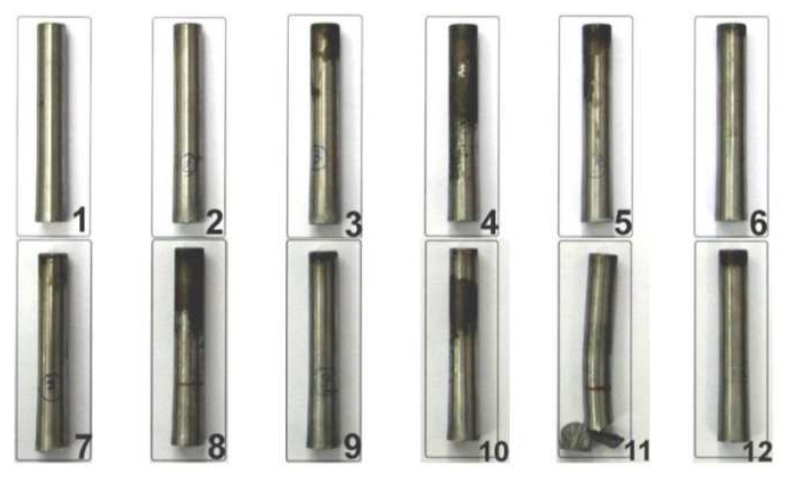

Fig. 3. NANOS-BA® steel samples after the Taylor tests [4].

With the Taylor test procedure it was established that the dynamic yield strength of NANOS-BA® steel equals $R_{e D}=1.9 \mathrm{GPa}$ for a strain rate of $2.7 \times 10^{3} \mathrm{~s}^{-1}$. The material demonstrates good plasticity under dynamic conditions, it remains consistent at impact velocities up to approx. $200 \mathrm{~m} / \mathrm{s}$ (Fig. 3). The increase in the yield strength of NANOS-BA® steel from $R_{e 02}=1.6 \mathrm{GPa}$ to $R_{e D}=1.9 \mathrm{GPa}$ with the increase of the strain rate from $8.0 \times 10^{-3} \mathrm{~s}^{-1}$ to $2.0 \times 10^{3} \mathrm{~s}^{-1}$ is a reliable result.

\subsection{J-C parameters identification}

At least few methods of identification of J-C material constants may be found in the literature [5-7]. In this work the parameters $\mathrm{A}, \mathrm{B}$ and $\mathrm{n}$ were determined from the true stress-strain curves obtained on the basis of quasi-static compression tests at room temperature. Firstly, the value of A constant was read from the graph as the yield strength. The value of $B$ and $n$ constants were determined by curve-fitting method adjusting the $\mathrm{J}$ $\mathrm{C}$ curve (with strain rate hardening and temperature softening effects blocked) to the true stress-strain curve (for data describing the plastic part of the curve) by the least squares method. The curve fitting was performed in the MATLAB software. The correlation coefficient for the curves was $\mathrm{R}=0.970$.

The value of the $\mathrm{C}$ constant (describing the dynamic strengthening of the material) was chosen to provide an increase of the yield strength of NANOS-BA® steel from 1.6 GPa as in quasi-static tests at the strain rate $8 \times 10^{-3} \mathrm{~s}^{-1}$ to $1.9 \mathrm{GPa}$ obtained during the Taylor test under strain rate $2.7 \times 10^{3} \mathrm{~s}^{-1}$. The $\mathrm{C}$-value determined in this way equalled $\mathrm{C}=0.01$ (Fig. 4).

In case of the fracture model, $\mathrm{D}_{1}, \mathrm{D}_{2}, \mathrm{D}_{3}$ constants have the greatest influence on the strain to fracture. To determine these values it is necessary to carry out tension and compression tests for the samples with different neck radius. The neck radius determines the initial value of the stress triaxiality given by relation:

$$
\frac{\sigma_{h}}{\sigma_{e q}}=\frac{1}{3}+\ln \left(1+\frac{a}{2 R}\right)
$$

where: $\sigma_{h}$ - mean stress, $\sigma_{e q}$ - equivalent stress, $a$ - radius of the specimen smallest cross section, $R$ - radius of curvature at the specimen neck.

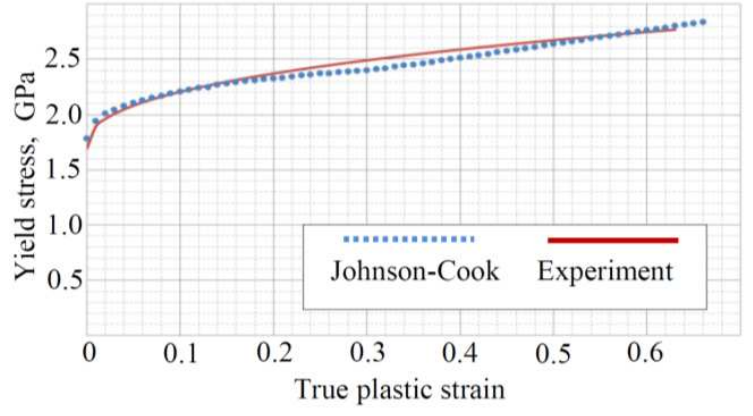

a

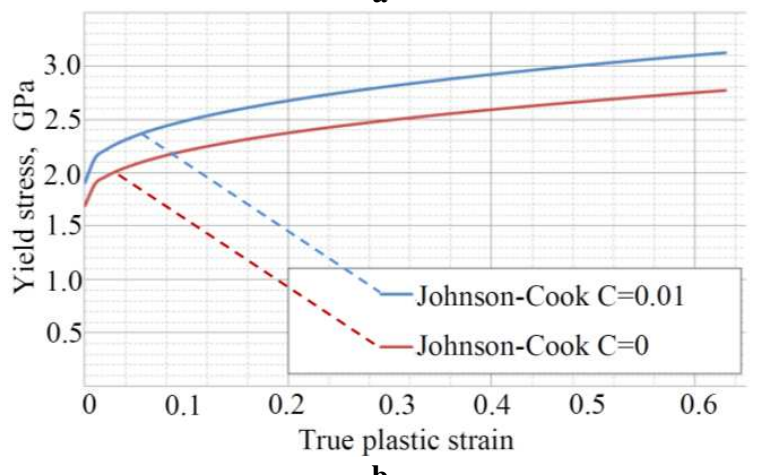

Fig. 4. Determination of constants $n$ and $C$ of the $J$ - $C$ model equation for NANOS-BA® steel: $a$ - plastic flow ( $n$ and $B$ constants); $b$ - dynamic yield stress as a function of strain rate (C constant).

In this work some simplifications had to be assumed because only unnotched samples were tested. During the mechanical tests, when the radius of the specimen curvature decreases the absolute value of stress triaxiality increases. For unnotched specimens in uniaxial quasi-static tests, the value of initial stress triaxiality was assumed as constant and equal to -0.33 for compression (negative triaxiality) and to 0.33 for tension. The corresponding experimental strains to fracture $(0.64$ in compression test and 0.13 in tension test) for these values were plotted on the equivalent plastic strain to fracture versus stress triaxiality graph. Then the values of $D_{1}, D_{2}, D_{3}$ constants were tuned in such a way that the exponential curve built from the equation 2 with $D_{4}=0$ and $D_{5}=0$ (Figure 5), passed as close as possible to these points (experimental strains to fracture).

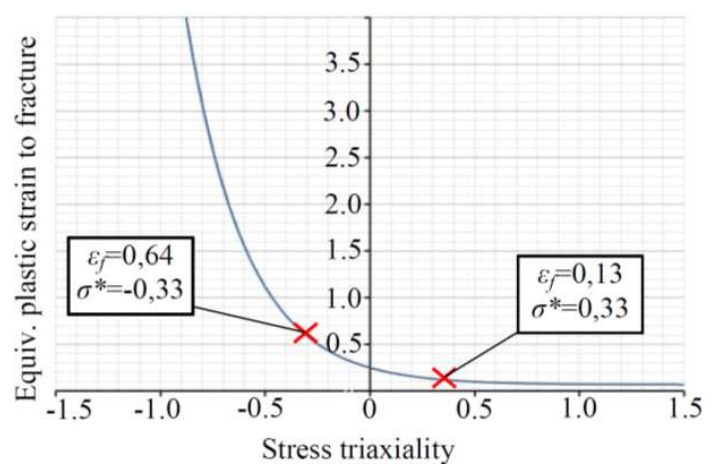

Fig. 5. The curve of the $J$-C fracture model for selected $D_{1}, D_{2}$, $D_{3}$ constants. 
Because only two points determined the curve the selected values of constants $D_{1}, D_{2}, D_{3}$ were treated only as initial. These values were then modified in a validation process to obtain stresses and strains similar to the experimental ones.

The influence of $\mathrm{D}_{4}$ and $\mathrm{D}_{5}$ constants (describing how the dynamic strengthening and thermal softening of the material affects its strain to failure) were omitted, assuming $\mathrm{D}_{4}=\mathrm{D}_{5}=0$. In this way, the initial values of $\mathrm{J}$ $\mathrm{C}$ flow and fracture model constants were determined (Table 1).

Table 1. The J-C model constants for NANOS-BA® steel.

\begin{tabular}{|c|c|c|c|c|c|c|c|c|c|c|c|}
\hline $\begin{array}{c}\boldsymbol{\rho}, \\
\mathbf{g} / \mathbf{c m}^{3}\end{array}$ & $\begin{array}{c}G, \\
\mathbf{G P a}\end{array}$ & $\begin{array}{c}\mathbf{A P a} \\
\mathbf{G}\end{array}$ & $\begin{array}{c}\mathbf{G P a} \\
\mathbf{G P}\end{array}$ & $\mathbf{C}$ & $\mathbf{n}$ & $\mathbf{m}$ & $\mathbf{D}_{\mathbf{1}}$ & $\mathbf{D}_{\mathbf{2}}$ & $\mathbf{D}_{\mathbf{3}}$ & $\mathbf{D}_{\mathbf{4}}$ & $\mathbf{D}_{\mathbf{5}}$ \\
\hline 7.85 & 76 & 1.51 & 1.57 & 0.01 & 0.35 & 1 & 0.07 & 0.18 & -3.5 & 0 & 0 \\
\hline
\end{tabular}

\subsection{Validation of the model}

Methodology of validation was based on numerical reproduction of previously performed material tests with the use of determined constants (Table. 1), subsequent comparison of the results and possible modification of JC parameters.

Compression tests were modelled to compare the force-displacement graphs, the way of deformation of the samples and the values of stress and strains at fracture obtained experimentally and numerically. Simulations were carried out in the ANSYS Autodyn software. The results of analysis for NANOS-BA® steel is shown in table 2. Three force-displacement curves are shown: for averaged experimental results and for the following two numerical variants:

1. variant $\mathrm{I}$ with the initial values of $\mathrm{J}-\mathrm{C}$ fracture model constants $(\mathrm{D} 1=0.07, \mathrm{D} 2=0.18, \mathrm{D} 3=-3.5)$ determined by curve fitting method;

2. variant II with the J-C fracture model constants (D1 $=0.09, \mathrm{D} 2=0.33, \mathrm{D} 3=-3$ ) modified to achieve the curve shape and the value of fracture strain more similar to experimental ones.

The use of the initial set of constants resulted in premature failure of the NANOS-BA ${ }^{\circledR}$ steel specimen for the displacement of the tester punch $\Delta \mathrm{z}=1.95 \mathrm{~mm}$.

Modification of the values of J-C fracture model constants increased the strength of the sample, and in consequence the moment of fracture of the sample was moved in the higher displacements direction to the value of $\Delta \mathrm{z}=4.8 \mathrm{~mm}$. Both the shapes of force-displacement curves as well as the values of characteristic stresses and strains obtained in experiments and simulations with the use of modified set of constants are very similar. Differences are visible only in the initial parts of the curves. This may be caused by the fact that values of forces and displacements in the experiments were recorded directly from the testing machine. Thus, at the initial stage of the test, these values could be affected by some errors due to the quality of the apparatus used, e.g. clearances between the components of the machine (stamps, jaws), compressibility of the hydraulic fluid, etc.
Table 2. Deformations, stress distribution and the force displacement curves obtained experimentally and numerically.

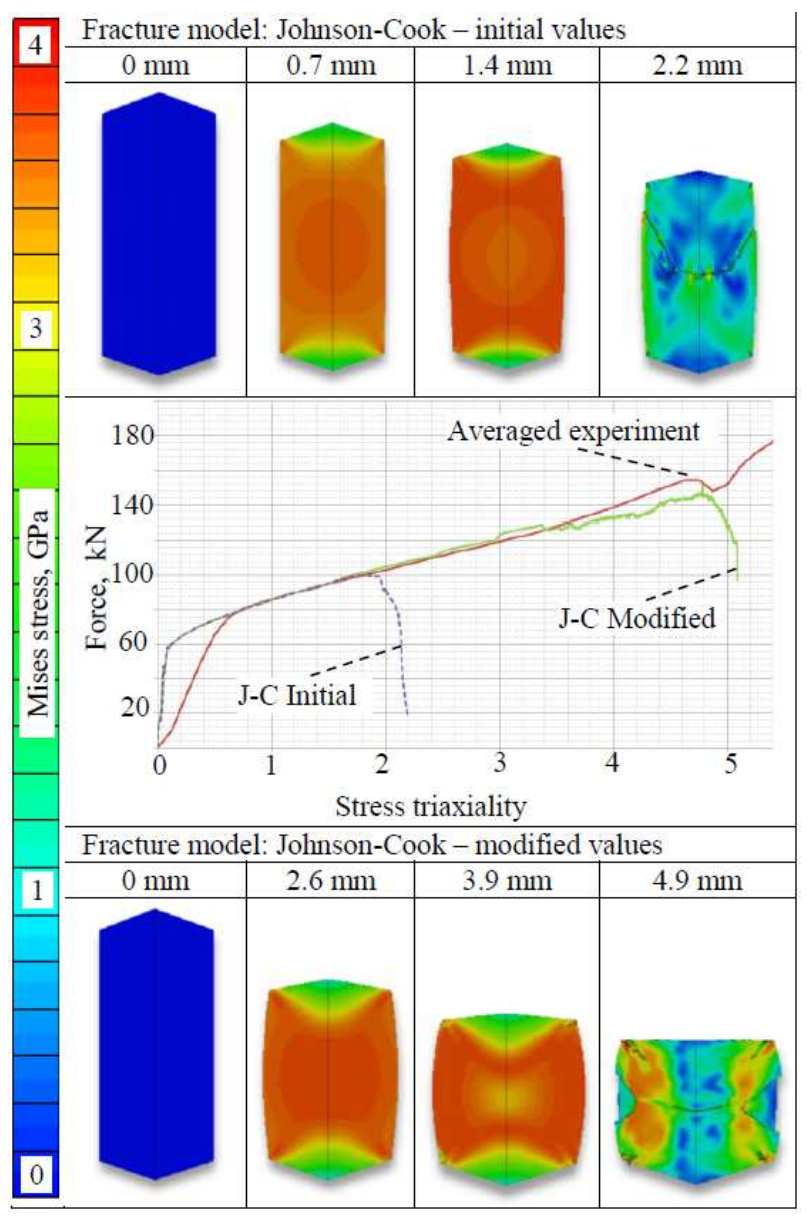

The Taylor test was reproduced to check the behaviour of the numerical model of NANOS-BA® steel under high strain rates $\left(2.5-3.2 \times 10^{3} \mathrm{~s}^{-1}\right)$. Thus, the graphs of sample shortening as a function of impact velocity as well as the deformation forms of samples obtained experimentally and numerically were compared.

To measure the shortening, gauge points 1 and 2 were placed on the front and back surfaces of the sample. The $x$ coordinate of the gauge points was measured in time (Fig. 6). The difference in the initial and final position of the points determined the length of the sample. In turn the difference between the initial and the final sample length constituted shortening of the sample. Comparison of the sample shortening values in function of the impact velocity showed satisfactory agreement between the simulation and experiment results. In both cases, there was an almost linear increase in sample shortening together with increasing impact velocity in the analysed velocity range. And the maximum difference in value was about $0.21 \mathrm{~mm}=$ $8.34 \%$. 

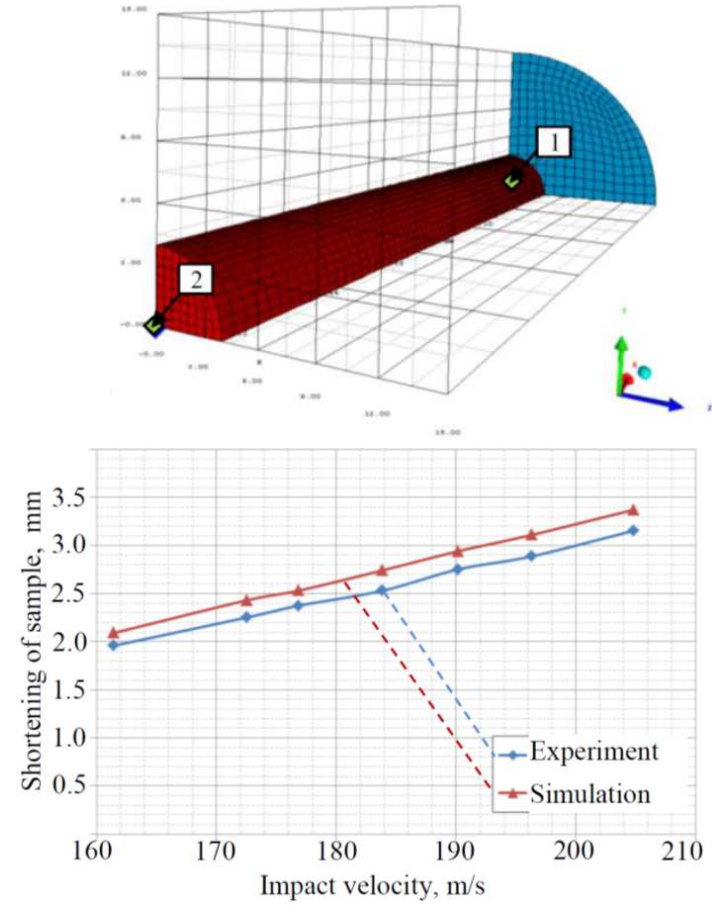

Fig. 6. Model of Taylor test and the shortening of samples in function of impact velocity.

The results of validation are collected in Table 3 . There are both qualitative (e.g. the way of failure of sample during compression tests) and quantitative (e.g. values of characteristic stresses or strains) parameters. The assessment of the compatibility ratio between the numerical and experimental results is highly subjective for qualitative parameters. In case of quantitative ones the correlation between the experiments and simulations was determined on the basis of a relative error. The following scale of fitting ratio was adopted:

1. very good adjustment for relative error $\Delta \mathrm{e} \leq 10 \%$;

2. satisfactory adjustment for relative error $\Delta \mathrm{e}=11$ $25 \%$;

3. poor adjustment for relative error $\Delta \mathrm{e}=26-40 \%$;

4. no adjustment for relative error $\Delta \mathrm{e}>41 \%$.

Table 3. The results of validation tests.

\begin{tabular}{|c|c|c|}
\hline Kind of test & Experiment & Simulation \\
\hline $\begin{array}{c}\text { Quasi-static compression } \\
\text { displacement curve }\end{array}$ & Satisfactory \\
\hline $\begin{array}{c}\text { The way of sample } \\
\text { failure }\end{array}$ & $\begin{array}{c}\text { Fracture } \\
\text { at an angle }\end{array}$ & Satisfactory \\
\hline Force at yielding point & $65 \mathrm{kN}$ & $\begin{array}{c}58 \mathrm{kN}, \Delta e=11 \%, \\
\text { Satisfactory }\end{array}$ \\
\hline Force at failure & $155 \mathrm{kN}$ & $\begin{array}{c}148 \mathrm{kN}, \Delta e=5 \%, \\
\text { very good }\end{array}$ \\
\hline $\begin{array}{c}\text { Punch displacement at } \\
\text { failure }\end{array}$ & $4.77 \mathrm{~mm}$ & $\begin{array}{c}4,8 \mathrm{~mm}, \Delta e=1 \%, \\
\text { very good }\end{array}$ \\
\hline $\begin{array}{c}\text { Shape of shortening- } \\
\text { impact velocity curve }\end{array}$ & Taylor Test & $\begin{array}{c}\text { Linear, } \\
\text { satisfactory }\end{array}$ \\
\hline $\begin{array}{c}\text { Shortening of samples } \\
\text { value }\end{array}$ & $1,96 \div 3,15 \mathrm{~mm}$ & $\begin{array}{c}\text { Max } \Delta e=8 \%, \\
\text { very good }\end{array}$ \\
\hline Failure of samples & no failure & $\begin{array}{c}\text { no failure, } \\
\text { very good }\end{array}$ \\
\hline
\end{tabular}

To summarize the data presented in Table 3 it can be concluded that the developed numerical model of the NANOS-BA® steel provide at least a satisfactory level of reproduction of the real behaviour of the materials in both the quasi-static as well as dynamic conditions.

\section{Applications of the numerical model}

The developed numerical model of the NANOS-BA® steel was used many times in analyses of ballistic protection structures and it proved its reliability and usefulness. Two exemplary numerical studies with the use of the model were shown on figures 7-8.

In the first analysis the developed numerical model was used to optimize the arrangement of holes in perforated armour plate made of the NANOS-BA® steel. The structure was considered as an pre-armour which together with the main armour of the vehicle provides protection against $7.62 \mathrm{~mm}$ armour piercing projectile of the B-32 type ( $3^{\text {rd }}$ level of STANAG 4569). A comparison of numerical and experimental results is shown in Figure 7.

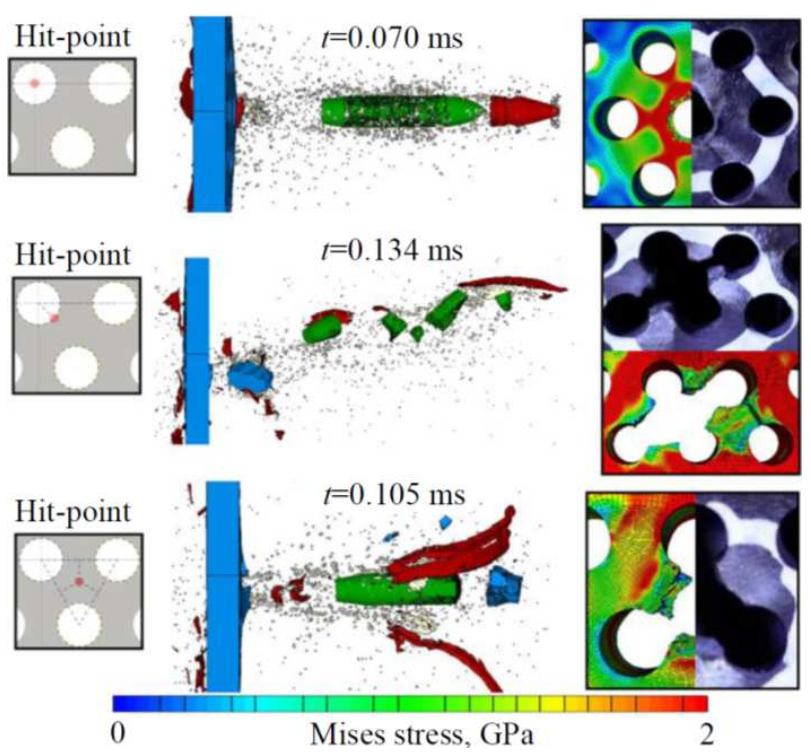

Fig. 7. Results of numerical analysis of $7.62 \times 54 \mathrm{~mm}$ API B32 projectile impact on the perforated plate: $\mathrm{a}$ - hit-point, $\mathrm{b}$ - condition of components for moment $t$ after impact, $\mathrm{c}$ - armour deformation after impact.

In the second example the NANOS-BA® steel was used as a main ballistic layer placed on the backing plate made of more ductile steel and surrounded by an aluminum cover. The whole construction together with a $8 \mathrm{~mm}$ thick main armour defeats the $14.5 \mathrm{~mm}$ armour piercing projectile of the B-32 type $\left(4^{\text {th }}\right.$ level of STANAG 4569). 


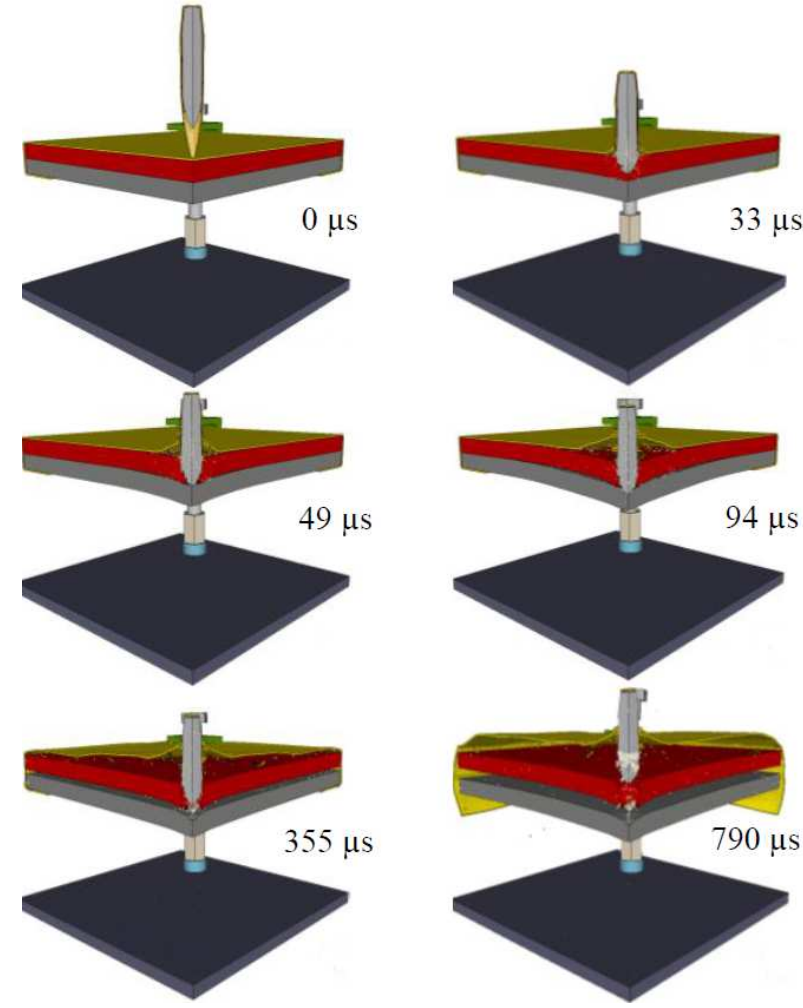

Fig. 8. Results of numerical analysis of $14.5 \mathrm{~mm} \mathrm{API} \mathrm{B32}$ projectile impact on the layered armour consisting NANOS$\mathrm{BA} \circledast$ steel plate.

\section{Summary}

The primary objective of the work was to develop the accurate and reliable constitutive model of high-strength nanostructured NANOS-BA® steel which could be used to numerical evaluation the effectiveness of armours. The model was built and then it was subjected to a validation process. On the basis of the validation, it has been concluded that the determined constants of the constitutive model provide satisfying accordance to the actual behavior of the material. Built and validated numerical model was used in many analyses of various projectile impact onto the different kinds of armours. Two examples were shown in the article. The results of the simulation were then compared with the outcomes of analogical experiments. The observance of only minor differences between the values of the relevant parameters prove that the model which has been developed allows the preliminary evaluation of the effectiveness of armours containing layers of highstrength nanostructured NANOS-BA® steel.

The determined set of material constants constitutes a valuable information for armour designers and CAE engineers.

\section{References}

1. W. Burian, B. Garbarz, J. Marcisz, A. Wiśniewski, A. Żak, P. Żochowski: Superhard nanostructured steels used in armours (Supertwarde stale nanostrukturalne do zastosowania $w$ pancerzach), Bellona, ISBN 978-83-11-14142-1 (2016)
2. G. R. Johnson, W. H. Cook. A constitutive model and data for metals subjected to large strains, high strain rates and high temperatures. 7th Int. Symp. on Ballistics (1983)

3. G. R. Johnson, W. H. Cook. Fracture characteristics of three metals subjected to various strains, strain rates, temperatures and pressures. Eng. Fract. Mech. 21, 31-48 (1985)

4. P. Żochowski. Numerical-experimental evaluation of protection capability of armours containing layers made of nanostructured steels (Numerycznoeksperymentalna ocena efektywności pancerzy zawierajacych warstwy ze stali nanostrukturalnych). Military Institute of Armament Technology, ISBN: 978-83-923882-5-8 (2017)

5. M. Nilsson. Constitutive model for Armox $500 T$ and Armox 600T at low and medium strain rates. s. 1 . Swedish Defence Research Agency, TR FOI-R1068-SE, (2003)

6. P. Skoglund, M. Nilsson, A. Tjernberg. Fracture modelling of a high performance armour Steel. Journal de Physique IV, France, 134, 197-202 (2006)

7. T. Børvik, S. Dey, A.H. Clausen. Perforation resistance of five different high strength steel plates subjected to small-arms projectiles. International Journal of Impact Engineering, 36, 948-964 (2009) 